\title{
INCREASE OF EFFICIENCY OF ACCELERATION OF THE TEST ELECTRON BUNCH BY SEQUENCE OF ELECTRON BUNCHES IN THE RECTANGULAR DIELECTRIC RESONATOR AT PLASMA FILLING
}

\author{
P.I. Markov, I.N. Onishchenko, G.V. Sotnikov \\ National Science Center “Kharkov Institute of Physics and Technology”, Kharkiv, Ukraine \\ E-mail:pmarkov@kipt.kharkov.ua
}

A result of numerical simulation of acceleration of the test electron bunch following a sequence of relativistic electron bunches in the rectangular dielectric resonator when filling the drift channel with plasma of different density is provided. We have found out that at change of plasma density the linear growth of energy gain of test bunch electrons is observed. It is connected with structure ordering of longitudinal accelerating electric field in the resonator and also with increase in its amplitude. It is due to that at periodic injection of drive bunches on resonator axis the areas with the increased plasma electrons density are formed.

PACS: 41.75.Ht, 41.75.Lx, 41.75.Jv, 96.50.Pw, 533.9

\section{INTRODUCTION}

For obtaining high rates of charged particles wakefield acceleration it is necessary to use single drive bunch with great charge [1].

Another way of the wakefield accelerating amplitude increasing is using of periodic drive bunches sequence with smaller charge [2 - 7]. This way is implemented in experimental installation IPENMA NSC KIPT "Almaz-2" in which the regular electron bunches sequence excites wakefield which eigen modes frequencies are equal or multiple to the bunches-repetition frequency of $2.805 \mathrm{GHz}$.

On this installation a carrying-out of experiments on electron bunches injection in the rectangular dielectric resonator with plasma filling is supposed. For explanation of the expected experimental results the numerical simulation of test electron bunch acceleration by relativistic electron bunches sequence in the rectangular dielectric resonator when filling the drift channel with plasma of different density is carried out. The results of these simulations are presented below.

\section{STATEMENT OF THE PROBLEM}

Rectangular dielectric waveguide under investigation represents the metal waveguide having the cross sizes $a \times b$ with two dielectric slabs (dielectric permittivity is equal to $\varepsilon$ ), lining opposite wide walls of a waveguide (Fig. 1). For obtaining the resonator we closed waveguide end faces by the conductive grids, transparent for electron bunches.

The drift channel of dielectric structure is filled with plasma. The on-axis electron drive sequence passes through the slowing-down structure and excites wakefield. In certain delay time $t_{d e l}$ after the last drive bunch the test bunch with a charge by 100 times smaller, than at the driver is injected in resonator and moves under wakefield influence of drive bunch sequence.

Parameters of drive sequence, except for a charge of bunches, were chosen such, as in the experimental installation "Almaz-2". Charge of the bunches was increased by 10 times.

Dielectric slab dimensions for given bunches and waveguide were calculated using theory of excitation of multizone dielectric waveguides [8,9].

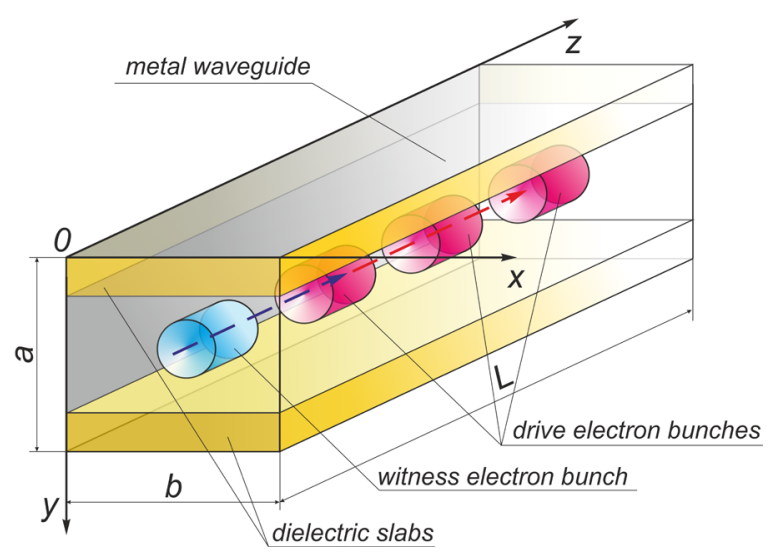

Fig. 1. Schematic view of a rectangular dielectric resonator. Yellow bricks show dielectric slabs, pink cylinders show drive electron bunches and blue cylinder shows test bunch

In Table the parameter of resonator, driver and witness bunches used in calculation are given.

Parameters used in calculation

\begin{tabular}{|c|c|c|}
\hline Waveguide & \multicolumn{2}{|l|}{$\mathrm{R} 26$} \\
\hline Dimensions $(a \times b)$ & \multicolumn{2}{|l|}{$45 \times 90 \mathrm{~mm}$} \\
\hline Operating frequency & \multicolumn{2}{|l|}{$5.606 \mathrm{GHz}$} \\
\hline $\begin{array}{l}\text { Repetition rate of drive bunches } \\
\text { sequence }\end{array}$ & \multicolumn{2}{|l|}{$2.803 \mathrm{GHz}$} \\
\hline $\begin{array}{l}\text { Slab dimensions (are located along } \\
\text { wide wall of a wave-guide) }\end{array}$ & \multicolumn{2}{|c|}{$8.182 \times 90 \mathrm{~mm}$} \\
\hline Working mode & \multicolumn{2}{|l|}{$\mathrm{LSM}_{21}$} \\
\hline Resonator length $L$ & \multicolumn{2}{|l|}{$31.919 \mathrm{~cm}$} \\
\hline Dielectrical permittivity $\varepsilon$ & \multicolumn{2}{|c|}{2.051 (Teflon) } \\
\hline Bunch energy $E_{0}$ & \multicolumn{2}{|l|}{$4.5 \mathrm{MeV}$} \\
\hline One bunch of drive sequence charge & \multicolumn{2}{|l|}{$2.6 \mathrm{nC}$} \\
\hline Test bunch charge & \multicolumn{2}{|l|}{$0.026 \mathrm{nC}$} \\
\hline Drive and test bunch diameter & \multicolumn{2}{|l|}{$10.0 \mathrm{~mm}$} \\
\hline \multirow{2}{*}{$\begin{array}{l}\text { Bunch axial RMS dimension } 2 \sigma \\
\text { (Gaussian charge distribution) }\end{array}$} & drive bunch & test bunch \\
\hline & $6.685 \mathrm{~mm}$ & $13.369 \mathrm{~mm}$ \\
\hline $\begin{array}{l}\text { Full bunch length used in PIC simu- } \\
\text { lation }\end{array}$ & $13.369 \mathrm{~mm}$ & $26.739 \mathrm{~mm}$ \\
\hline Plasma density $n_{p}$ & \multicolumn{2}{|c|}{$10^{9} \ldots 10^{10} \mathrm{~cm}^{-3}$} \\
\hline Delay time of test bunch $t_{d e l}$ & \multicolumn{2}{|l|}{$0.08966 \mathrm{~ns}$} \\
\hline Relation of $m_{i} / m_{e}$ of model plasma & \multicolumn{2}{|l|}{100} \\
\hline
\end{tabular}

It should be pointed that if to choose Teflon as dielectric, for R26 waveguide at any orientation of plates the 
solution is not exist at choice of the main mode of $\mathrm{LSM}_{21}$ or $\mathrm{LSE}_{11}$ with frequency of $2.803 \mathrm{GHz}$ which is used in the "Almaz-2" accelerator. Nevertheless, for the doubled frequency of $5.606 \mathrm{GHz}$ it is possible to choose $\mathrm{LSM}_{21}$ as operation mode.

\section{STEPS OF CALCULATIONS EXECUTION}

The analysis of test electron bunch acceleration by drive bunch sequence was carried out by means of numerical 3D PIC code in the following way:

1. The dielectric structure drift channel was filled with the macroparticles modeling plasma with some density $n_{p 1}$.

2. The given number $N_{d b}$ of drive bunches was injected into the investigated structure.

3. Later on the delay time $t_{d e l}$ after the last drive bunch injection the test bunch was injected and then it moved up to the system output end in the electromagnetic field created by drive bunches.

4. From the calculated values of electrons energies of the test bunch, which was near output end face of the structure, maximum energy was determined. Difference between this energy and initial energy $E_{0}$ was taken as test bunch energy gain $\Delta E_{w}$.

5. Varying number of drive bunches, we received dependence of test bunch electrons energy gain on number of drive bunches $\Delta E_{w}\left(N_{d b}\right)$ for plasma with density $n_{p 1}$.

6. Further we filled the drift channel of structure with plasma with other density $n_{p 2}$ and calculated $\Delta E_{w}\left(N_{d b}\right)$ again for case of filling the drift channel with plasma with density $n_{p 2}$.

7. Repeating described above steps several times we as a result have obtained dependence of test bunch electrons energy gain $\Delta E_{w}\left(N_{d b}, n_{p}\right)$, both from number of drive bunches $N_{d b}$, and from plasma density $n_{p}$.

\section{RESULTS OF 3D-PIC CODE SIMULATION}

In Fig. 2 the obtained accelerated test bunch energy gain $\Delta E_{w}$ versus number of drive bunches sequence varying $N_{d b}$ for different values of plasma density $n_{p}$ in the range from 0 to $10^{10} \mathrm{~cm}^{-3}$ are shown. At that $\Delta E_{w}\left(N_{d b}, n_{p}\right)$ is shown in the form of curves in the $n_{p}=$ const planes.

For the obtained dependence analysis at first we will project the curves shown in Fig. 2, on the plane passing through the axis $\Delta E_{w}$ parallel to axis $N_{d b}$ marked in Fig. 2 by the yellow color. These projections are shown in Fig. 3.

Curves in Fig. 3 clearly demonstrate step behavior of energy gain of the accelerated test bunch at change of drive bunches number. At the first stage of each step the linear growth of the accelerated test bunch energy with increase in number of drive sequence bunches is observed. At the second stage energy of a test bunch practically does not change at varying of drive bunches number. The step behavior $\Delta E_{w}$ at $N_{d b}$ change was al- ready described by us earlier [10] at research of test bunch acceleration by a sequence of relativistic electron bunches in the cylindrical dielectric resonator without a plasma in drift channel.

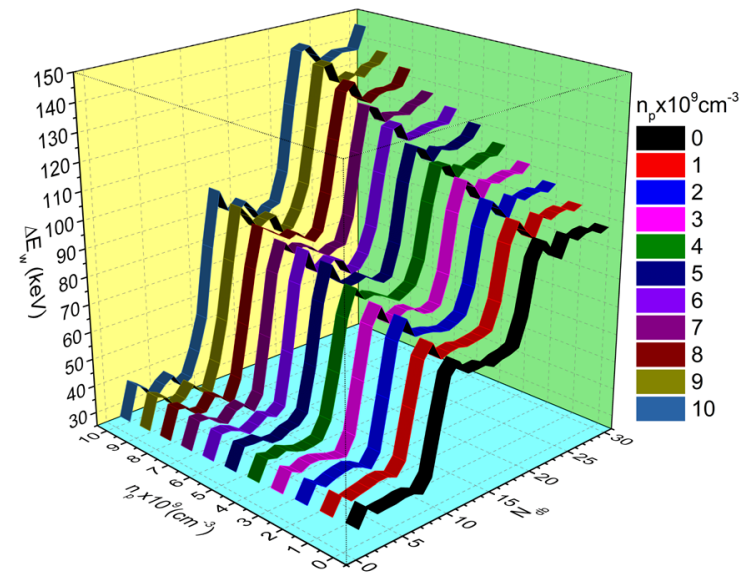

Fig. 2. The accelerated test bunch energy gain $\Delta E_{w}$ versus number of drive bunches sequence varying $N_{d b}$ for different values of plasma density $n_{p}$ in the range

from 0 to $10^{10} \mathrm{~cm}^{-3}$ in the form of curves in the $n_{p}=$ const planes

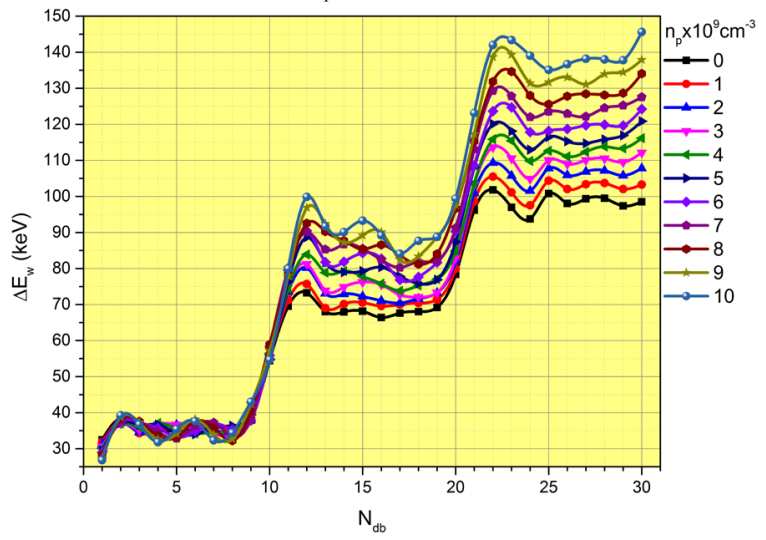

Fig. 3. A projection of the curves shown in Fig. 2, on the plane passing through the axis $\Delta E_{w}$ parallel to an axis $N_{d b}$ marked in Fig. 2 by the yellow colour

As it has been noted above, the studied dielectric resonator is tuned on mode of $\mathrm{LSM}_{21}$ of oscillations with operating frequency of $5.606 \mathrm{GHz}$, and the drive sequence is injected with the half repetition rate equal to $2.803 \mathrm{GHz}$. In our case length of the resonator $L$ has been chosen equal to $6 \lambda$, where $\lambda$ is the electromagnetic field wavelength with operating frequency in the resonator. At the same time can be no more than $N_{d b}^{s}=L /(2 \lambda)$ bunches in the studied resonator. We assumed the length of the resonator equal to $L=6 \lambda$, therefore $N_{d b}^{s}=3$. In linear approach at $N_{d b}$ change from 1 to $N_{d b}^{s}$ fields after the last drive bunch are summed up and increased linearly depending on the $N_{d b}$. However, the self-consistent numerical simulation carried out by us has shown that the increase in fields is observed only for the first $N_{d b}^{s}-2$ bunches, i.e., in our case, for one bunch. We believe that it is connected with that in above mentioned estimation the field of transient radiation and "quenching wave" have not been considered [11]. 
After the drive bunch leaves the resonator from output end face of the resonator the wakefield is reflected and moves to its input end face. Group speed of the principal mode is $v_{g}=0.53 c$, where $c$ is light speed. Therefore for the resonator of the length $L=6 \lambda$ through time, equal to $t=L / v_{g}$, the backward wave will reach input end face of the resonator.

Thus, at injection of the ninth drive bunch the wakefield created by this bunch adds with the wave reflected from input end face of the resonator. This wave affects test bunch electrons and additionally accelerate them that is observed in the form of the growing stage of step dependence in Fig. 3.

Also in Fig. 3 the growth of test bunch energy gain $\Delta E_{w}$ at plasma density increase is visible. At that it is possible to notice that with varying of plasma density the steps height increases with $n_{p}$ increase, almost, linearly.

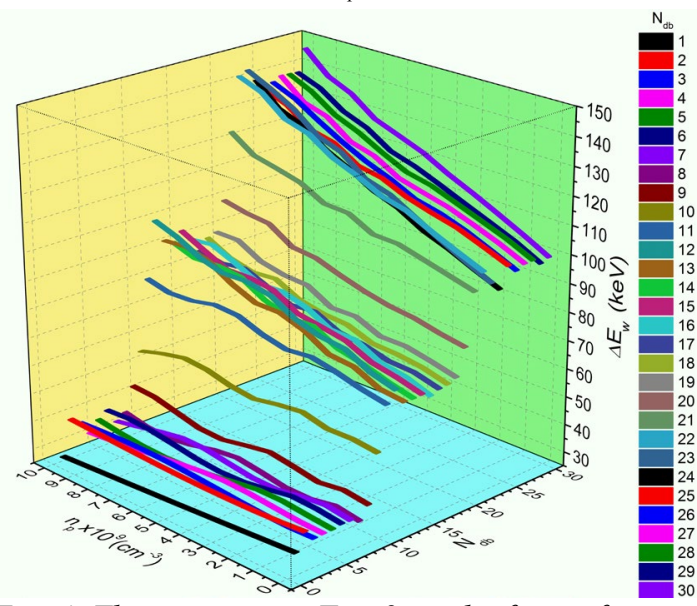

Fig. 4. The same, as in Fig. 2, in the form of curves in the $N_{d b}=$ const planes

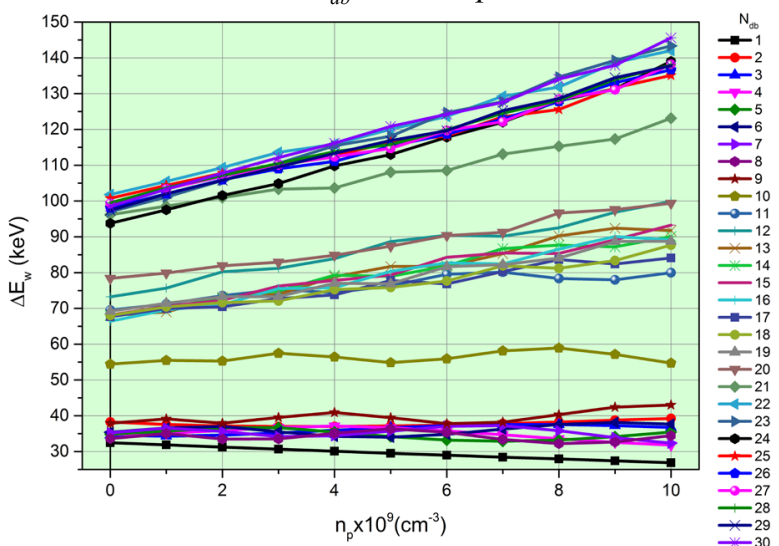

Fig. 5. Projection of the curves shown in Fig. 4, on the plane passing through axis $n_{p}$ parallel to $\Delta E_{w}$

axis (i.e. parallel to the plane marked in Fig. 4 by the green colour)

In order to more clearly demonstrate linear growth $\Delta E_{w}$ with $n_{p}$ increase, in Fig. 4 the dependence $\Delta E_{w}\left(N_{d b}, n_{p}\right)$ presented on Fig. 2 is shown in the form of curves in the $N_{d b}=$ const planes.

Further we will project the curves shown in Fig. 4, on the plane passing through axis $n_{p}$ parallel to axis $\Delta E_{w}$ (i.e. parallel to the plane marked in Fig. 4 by the green colour). These projections are shown in Fig. 5.
It is seen in Fig. 5 that when plasma density $n_{p}$ varying, almost linear growth of energy gain $\Delta E_{w}$ of test bunch electrons if number of drive bunches $N_{d b}>10$ is observed

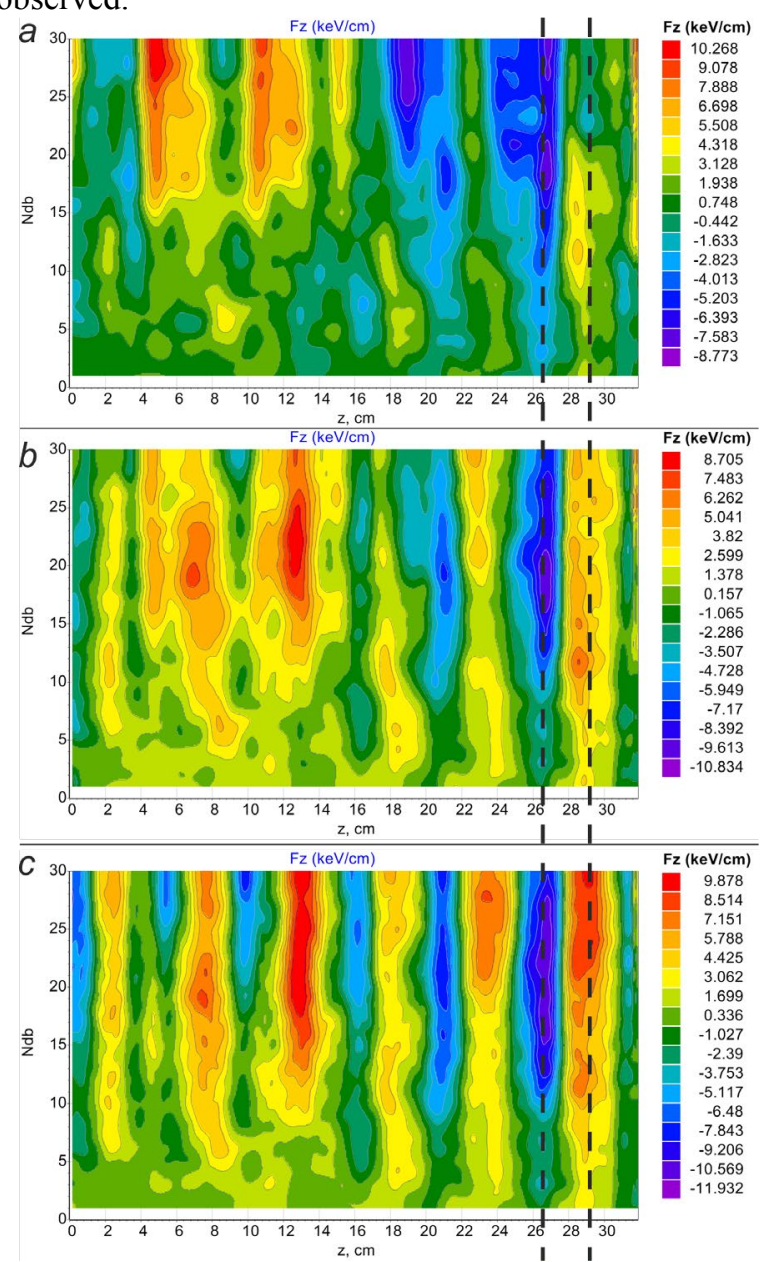

Fig. 6. Colour maps and level lines for longitudinal components of the Lorentz force $F_{z}(z)$ acting on test electron

at resonator axis depending on number of the injected drive bunches $N_{d b}$ at different plasma density values:

a) $n_{p}=0$; b) $n_{p}=5 \times 10^{9} \mathrm{~cm}^{-3}$; c) $n_{p}=1 \times 10^{10} \mathrm{~cm}^{-3}$.

The dotted line has schematically shown the test bunch position

To explain $\Delta E_{w}$ growth at plasma density increase, let's analyze structure of longitudinal field $E_{z}(z)$ depending on number of the injected drive bunches for several $n_{p}$ values. In Fig. 6 dependences of longitudinal force components $F_{z}\left(z, N_{d b}\right)=-|e| E_{z}\left(z, N_{d b}\right)$ are given at resonator axis in the form of colour map and level lines for different plasma density values $n_{p}$ varying from 0 to the $10^{10} \mathrm{~cm}^{-3}$. Times, for which longitudinal forces $F_{z}$ in Fig. 6 are given, correspond to the moments when the last drive bunch of sequence approaches output end face of the resonator. Vertical dotted straight lines schematically show the test bunch position.

From Fig. 6 follows that at increase in plasma density the longitudinal accelerating electric field structure ordering and also increase in its amplitude in area where there is a test bunch is observed. 
The reason of this, from our point of view, is the next. Electrons of each drive bunch push out plasma electrons to the drift area periphery. Behind the driver the area with the excess positive charge created by plasma ions is formed. It leads to appearance of the field forcing the plasma electrons, which are in abundance on the periphery, to move to resonator axis. As a result at periodic injection of drive bunches on resonator axis the areas with high plasma electrons concentration are formed. In confirmation of this in Fig. 7 the dependence of plasma electron density on resonator axis $n_{\text {peat axes }}$ versus longitudinal coordinate $z$ for different values of initial plasma density $n_{p}$ is shown.

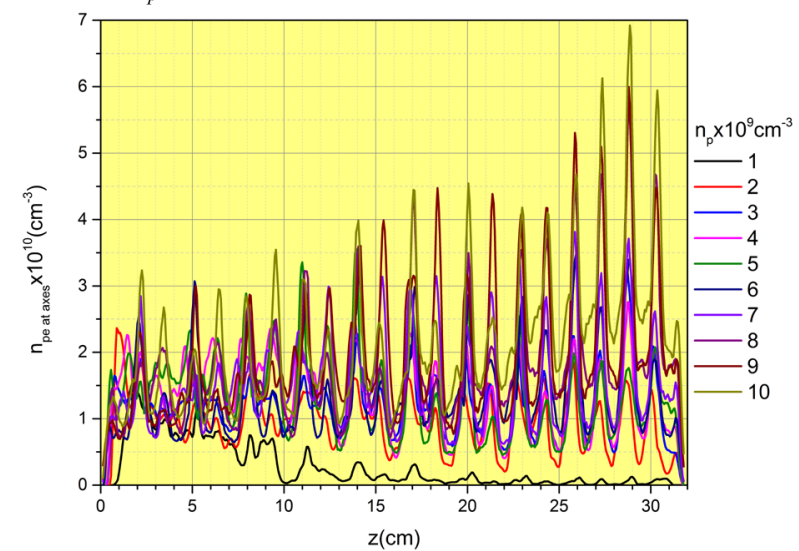

Fig. 7. Plasma electron density on resonator axis $n_{\text {pe at axes }}$ versus longitudinal coordinate $z$ for different values of initial plasma density $n_{p}$

One can see from Fig. 7 that when the initial plasma density in system is higher, oscillations of the plasma electrons density on resonator axis are higher also. These density oscillations lead to the changes of longitudinal electric field $E_{z}(z)$ causing its structure ordering and increase in amplitude shown in Fig. 6.

\section{CONCLUSIONS}

At study of test electron bunch acceleration in the dielectric resonator with plasma filling in the field of drive electrons bunches sequence we have found out that:

- When changing a number of bunches in regular sequence the step growth of the accelerated test bunch energy gain is observed.

- If plasma density changes in range from $10^{9} \mathrm{~cm}^{-3}$ to $10^{10} \mathrm{~cm}^{-3}$ and the drive sequence contains more than 10 bunches the linear growth of test bunch electrons energy gain is observed.

- This is due to the ordering of the structure of the longitudinal accelerating electric field, as well as to an increase in its amplitude in the region where the test bunch is located.

- This, by-turn, is due to fact the areas with increased density of plasma electrons are formed on axis of the resonator during periodic injection of drive bunches. At that, the higher the initial plasma density in system caused the higher the oscillations of plasma electrons density on resonator axis.

\section{ACKNOWLEDGMENT}

Work supported by NAS of Ukraine program "Perspective investigations on plasma physics, controlled thermonuclear fusion and plasma technologies", project P-1/63-2017 "Wakefield acceleration of electrons in multi-zone dielectric and plasma-dielectric structures".

Work was partially supported by the Ukrainian budget program "Support for the most important directions of scientific researches" (КПКВК 6541230).

\section{REFERENCES}

1. I. Blumenfeld, C.E. Clayton, F.-J. Decker, et al. Energy doubling of $42 \mathrm{GeV}$ electrons in a metre-scale plasma wakefield accelerator // Nature. 2007, v. 445, p. 741.

2. A.K. Beresin, Ya.B. Fainberg, L.I. Bolotin, A.M. Egorov, V.A. Kiselev. Experimental investigation of interaction of the modulated relativistic bunches with plasma // Pis'ma v ZTF. 1971, v. 13, p. 498-503 (in Russian).

3. A.K. Beresin, Ya.B. Fainberg, V.A. Kiselev, et al. Wake-field excitation in a plasma by pulse of relativistic electrons containing of controlled number of short bunches // Fizika plazmy. 1994, v. 20, № 7,8, p. 663-670 (in Russian).

4. K. Nakajima. Plasma wake-field accelerator driven by a train of multiple bunches // Particle Accelerators. 1990, v. 32, p. 209-218.

5. I.N. Onishchenko, V.A. Kiselev, A.F. Linnik, G.V. Sotnikov. Concept of dielectric wakefield accelerator driven by a long sequence of electron bunches // IPAC 2013. Proceedings of the 4th International Particle Accelerator Conference. 2013, p. 1259-1261.

6. V. Kiselev, A. Linnik, V. Mirny, N. Zemliansky, R. Kochergov, I. Onishchenko, G. Sotnikov, Y. Fainberg. Dielectric wake-field generator // BEAMS 1998. Proceedings of the 12th International Conference on High-Power Particle Beams. 1998, p. 756-759.

7. I.N. Onishchenko, G.V. Sotnikov. Synchronization of Wakefield Modes in the Dielectric Resonator // Technical Physics. 2008, v. 53, № 10, p. 1344-1349.

8. C. Wang, J.L. Hirshfield. Theory for wakefields in a multizone dielectric lined waveguide // Phys. Rev. ST Accel. and Beams. 2006, v. 9, p. 031301.

9. G.V. Sotnikov, I.N. Onishchenko, J.L. Hirshfield, T.C. Marshall. A five-zone two-channel dielectric wakefield structure for two beam acceleration experiments at argonne national laboratory // Problems of Atomic Science and Technology. Series "Nuclear Physics Investigations”. 2008, № 3, p. 148-152.

10. P.I. Markov, I.N. Onishchenko, G.V. Sotnikov. Increase of efficiency of acceleration of the test electron bunch by sequence of electron bunches in the dielectric resonator // Problems of Atomic Science and Technology. Series "Plasma Physics”. 2018, № 6, p. 152-155.

11. V.A. Balakirev, I.N. Onishchenko, D.Yu. Sidorenko, G.V. Sotnikov. Excitation of a wake field by a relativistic electron bunch in a semi-infinite dielectric waveguide // Journal of Experimental and Theoretical Physics. 2001, v. 93, № 1, p. 33-42.

Article received 16.10.2019 


\title{
ПОВЫШЕНИЕ ЭФФЕКТИВНОСТИ УСКОРЕНИЯ ТЕСТОВОГО ЭЛЕКТРОННОГО СГУСТКА ПОСЛЕДОВАТЕЛЬНОСТЬЮ ЭЛЕКТРОННЫХ СГУСТКОВ В ПРЯМОУГОЛЬНОМ ДИЭЛЕКТРИЧЕСКОМ РЕЗОНАТОРЕ ПРИ ПЛАЗМЕННОМ ЗАПОЛНЕНИИ
}

\author{
П.И. Марков, И.Н. Онищенко, Г.В. Сотников
}

Представлены результаты численного моделирования ускорения тестового сгустка электронов, следующего за последовательностью релятивистских электронных сгустков в прямоугольном диэлектрическом резонаторе при заполнении канала дрейфа плазмой с различной плотностью. Обнаружено, что при изменении плотности плазмы наблюдается линейный рост увеличения энергии электронов тестового сгустка. Это связано с упорядочением структуры продольного ускоряющего электрического поля, а также с увеличением его амплитуды, что происходит потому, что при периодической инжекции драйверных сгустков на оси резонатора образуются области с повышенной концентрацией плазменных электронов.

\section{ПІДВИЩЕННЯ ЕФЕКТИВНОСТІ ПРИСКОРЕННЯ ТЕСТОВОГО ЕЛЕКТРОННОГО ЗГУСТКА ПОСЛІДОВНІСТЮ ЕЛЕКТРОННИХ ЗГУСТКІВ У ПРЯМОКУТНОМУ ДІЕЛЕКТРИЧНОМУ РЕЗОНАТОРІ ПРИ ПЛАЗМОВОМУ ЗАПОВНЕННІ}

\section{П.І. Марков, І.М. Оніщцеко, Г.В. Сотніков}

Представлено результати чисельного моделювання прискорення тестового згустка електронів, що прямує за послідовністю релятивістських електронних згустків у прямокутному діелектричному резонаторі при заповненні каналу дрейфу плазмою з різною щільністю. Виявлено, що при зміні щільності плазми спостерігається лінійне зростання збільшення енергії електронів тестового згустка. Це пов'язане з упорядкуванням структури поздовжнього прискорювального електричного поля, а також зі збільшенням його амплітуди, що відбувається тому, що при періодичній інжекції драйверних згустків на осі резонатора утворюються області 3 підвищеною концентрацією плазмових електронів. 